\title{
ÁREAS CRÍTICAS NA AQUISIÇÃO DO PORTUGUÊS EM MOÇAMBIQUE
}

\section{Critical Areas in the Acquisition of Portuguese in Mozambique}

Carlito António COMPANHIA

Universidade Eduardo Mondlane ccompanhia@yahoo.com.br https://orcid.org/0000-0001-6635-0415

\begin{abstract}
RESUMO: O presente artigo tem como objectivo descrever as áreas críticas na aquisição do português em Moçambique. Do ponto de vista metodológico, o estudo adota uma abordagem qualitativa e toma como base dados naturais extraídos de entrevistas semi-estruturadas produzidas por aprendentes do português que se encontram num estágio intermediário de aquisição. Os resultados deste estudo mostram que as áreas críticas da gramática de interlíngua dos aprendentes do português em Moçambique se situam ao nível da alteração das propriedades de seleção categorial, da escolha do tempo verbal, da omissão do artigo e do encaixe de orações subordinadas. PALAVRAS-CHAVE: Áreas Críticas; Aquisição do Português; Moçambique.
\end{abstract}

ABSTRACT: This article aims to describe the critical areas in the acquisition of Portuguese in Mozambique. From the methodological point of view, the study adopts a qualitative approach and takes natural data from semi-structured interviews produced by Portuguese learners in an intermediate stage of acquisition. The results of this study show that the critical areas of Portuguese learners' interlanguage grammar include the change of the verbal categorical selection properties, the choice of verbal tense, the omission of the articles and the embedding of subordinate clauses. KEYWORDS: Critical Areas; Portuguese Acquisition; Mozambique.

\section{INTRODUÇÃO}

Em Moçambique, à semelhança de muitos países africanos pós-coloniais, o português é, para a maior parte dos falantes, uma língua segunda (L2). A situação de

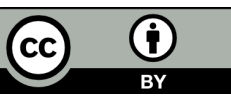


contacto linguístico ${ }^{1}$ em que ela se encontra com as línguas do grupo bantu (LB) e a ausência de uma exposição à norma europeia do português (PE), que é o modelo-alvo, são factores fundamentais que explicam o desencadeamento de uma nova variedade desta língua - o Português de Moçambique (PM) (GONÇALVES, 2002; 2010a). Este facto tem implicações no que respeita ao processo de aquisição desta língua uma vez que, tal como refere Gonçalves (2002, p. 344), as evidências que poderiam conduzir à fixação de parâmetros da língua-alvo são menos robustas. Consequentemente, a gramática dos aprendentes caracteriza-se por apresentar desvios relativamente ao PE ao nível das diferentes componentes.

O conhecimento das áreas críticas na aquisição do português em Moçambique, isto é, das dificuldades dos aprendentes no estabelecimento das propriedades gramaticais desta língua, constitui uma importante fonte de informação sobre as etapas de desenvolvimento linguístico dos aprendentes no processo de aquisição. Nesse sentido, tendo em consideração que o sucesso da aquisição do português se torna mais dependente do acesso ao ensino formal - dado o contexto social em que a sua gramática emerge este tipo de informação tem relevância no que se refere à elaboração de programas e produção de materiais de ensino desta língua.

O presente artigo situa-se neste âmbito geral e tem como objectivo descrever as áreas críticas na aquisição do português por parte dos aprendentes em Moçambique. Com efeito, embora já estejam disponíveis estudos que façam uma descrição de diferentes aspectos relacionados com as gramáticas de interlíngua dos aprendentes do português em Moçambique $^{2}$, este estudo pretende ser mais um contributo para a sistematização das dificuldades dos aprendentes do português em Moçambique, sobretudo no estágio intermediário de aquisição. Na verdade, tal como afirma Gonçalves (2010a):

o conhecimento de estágios intermédios de aquisição permite aceder às hipóteses que emergem nas gramáticas da interlíngua, tornando assim possível captar 'por dentro' o processo cognitivo que dá origem à nova gramática do PM, e mostrando as dificuldades de aprendentes com L1 bantu no estabelecimento das propriedades gramaticais da língua-alvo, o PE (p. 198).

\footnotetext{
${ }^{1}$ Veja-se Gonçalves e Chimbutane (2015) para uma visão sobre as assimetrias que se observam nas mudanças induzidas por contacto linguístico em Moçambique.

${ }^{2}$ Veja-se Companhia (2017) para uma visão panorâmica dos estudos sobre a gramática de interlíngua dos aprendentes do português em Moçambique.
} 
$\mathrm{O}$ artigo estrutura-se da seguinte maneira: a seguir a presente introdução, fazse um breve enquadramento teórico em torno do conceito de aquisição de L2. Depois, apresenta-se a metodologia de investigação adotada. Em seguida, apresentam-se e descrevem-se os resultados da análise dos dados. Finalmente, traçam-se as considerações finais que decorrem deste estudo.

\section{AQUISIÇÃO DA LINGUAGEM}

O termo ‘aquisição' dá conta do processamento mental das estruturas gramaticais de uma língua. Na literatura, costuma fazer-se uma distinção entre 'aquisição' e 'aprendizagem' de língua. De acordo com Krashen (1988, p. 1-2), o conceito de 'aquisição' refere-se a um processo implícito e subconsciente de internalização de regras gramaticais de uma língua e resulta da interação que os aprendentes estabelecem com a língua-alvo através de um processo de comunicação natural. Por seu turno, tal como refere o autor, o termo 'aprendizagem' diz respeito ao processamento explícito e consciente das regras da gramática de uma língua e resulta da experiência de instrução formal que os aprendentes vivem.

No processo de aquisição de uma L1, a Gramática Universal (GU) constitui o estado inicial da aquisição, sendo que a criança constrói a representação mental da sua língua com base no input a que está exposta (KLEIN e MARTOHARDJONO, 1999, p. 11). A tarefa da criança consiste, por um lado, na internalização mental das formas lexicais da língua com as suas propriedades fonológicas, sintácticas e semânticas, (RAPOSO, 1992, p. 55). Por outro lado, segundo o mesmo autor, a aquisição de L1 implica a fixação de parâmetros da GU que têm relevância para a língua que a criança está a adquirir. Uma vez fixados todos os valores de parâmetro, pode dizer-se que a criança adquiriu a sua gramática nuclear (core grammar, em inglês).

A aquisição de L2 refere-se ao processo através do qual os indivíduos adquirem uma língua diferente da sua L1 (RITCHIE e BHATIA, 1996, p. 1). O processo da aquisição de L2 distingue-se do processo da aquisição da L1 não só em relação ao estágio inicial da aquisição, como também em relação ao grau de sucesso no seu estágio final, dado que a gramática atingida pelos aprendentes de uma L2 nem sempre converge plenamente com a gramática da língua-alvo. Assim, diferentemente do que se verifica na aquisição da L1, no estágio inicial, os aprendentes de uma L2 já possuem o conhecimento prévio da sua L1, o qual pode afectar de forma particularmente crítica o processo de aquisição de L2. Na literatura, o papel da L1 dos aprendentes tem sido abordado no âmbito da transferência linguística. Odlin (2003, p. 436-437) considera que o fenómeno da transferência consiste 
na influência resultante das similaridades e diferenças entre a língua-alvo e qualquer outra língua que tenha sido previamente adquirida (e talvez de forma imperfeita), podendo afectar todos os subsistemas linguísticos, incluindo a pragmática, semântica, sintaxe, morfologia, fonologia, fonética e ortografia.

Durante o processo de aquisição de L2, os aprendentes atravessam diversos estágios em direção à gramática da língua-alvo, construindo sistemas gramaticais provisórios e intermédios denominados “interlínguas" (SELINKER, 1974, p. 35). As interlínguas constituem sistemas de conhecimento transitórios diferentes quer da L1, quer da língua-alvo e que possuem consistência interna. Por isso, estes sistemas devem ser descritos como línguas naturais e não como "gramáticas selvagens" (GOODLUCK, 1986, p. 55), evitando-se deste modo, a "subestimação ou sobrestimação" da competência linguística dos aprendentes (LAKSHMANAN e SELINKER, 2001, p. 339).

As gramáticas de interlíngua caracterizam-se por serem dinâmicas e por estarem num processo contínuo de reestruturação (GASS; SELINKER, 2001; ELLIS, 2008). De acordo com Ellis (2008, p. 442), a reestruturação refere-se às mudanças qualitativas que ocorrem na interlíngua dos aprendentes em determinados estágios do seu desenvolvimento linguístico. Para o autor, nesse processo, emerge uma série de representações da interlíngua que constituem um continuum de gramáticas transitórias, resultantes das tentativas dos aprendentes de atingirem uma competência plena na língua-alvo. $\mathrm{O}$ autor considera que tal continuum de interlíngua consiste de uma série de gramáticas sobrepostas; cada gramática partilha algumas regras da gramática anterior, sendo mais complexa relativamente à gramática precedente.

As gramáticas de interlíngua são intrinsecamente variáveis, de tal modo que os aprendentes de uma L2 podem variar entre o uso de formas corretas e o uso de formas incorretas em relação à norma da língua-alvo (ELLIS, 2008, p. 117). Nalguns casos, as formas incorretas podem resultar de tentativas de verificação de diferentes hipóteses sobre a forma como a língua-alvo é construída. Na literatura sobre a aquisição de L2, estas formas incorretas recebem o nome de 'erros de desenvolvimento' e, do ponto de vista psicolinguístico, incluem, entre outros processos, a simplificação das estruturas e elementos da língua-alvo, a sobregeneralização de algumas estruturas da língua-alvo e a transferência.

Na maior parte dos casos, no final do processo de reestruturação gramatical, a representação da língua-alvo por parte do aprendente pode não convergir com a língua-alvo. Por outras palavras, diferentemente do que acontece na aquisição de L1, o desenvolvimento em direção à gramática da língua-alvo pode não ser totalmente bem 
sucedido, sendo que o último nível de proficiência alcançado pelo aprendente nem sempre é semelhante ao de falantes que aprendem essa mesma língua como L1. O termo "fossilização" foi proposto por Selinker (1974, p. 36) para explicar este fenómeno e alberga os itens linguísticos, regras e subsistemas que os aprendentes de uma L2 tendem a conservar na sua gramática de interlíngua.

Os investigadores que trabalham na área da Aquisição de Língua Segunda se interessam em compreender os factores da fossilização, tentando, igualmente, prever as formas particulares da interlíngua potencialmente fossilizáveis. Long (2003, p. 516-517) destaca a falta de sensibilidade ao input associada à saliência perceptiva das estruturas da língua-alvo. Na óptica do autor, a sensibilidade ao input compreende a habilidade de os aprendentes identificarem as propriedades das estruturas da língua-alvo no input, enquanto a saliência perceptiva diz respeito à frequência destas mesmas estruturas no input. Tomando como base o trabalho de Todeva (1992), o autor identifica um conjunto de "categorias linguísticas de alto risco" potencialmente candidatas à fossilização destacando-se, nomeadamente, as categorias em que não existe uma relação formafunção como é o caso das regras semi-produtivas, cujas exceções constituem conjuntos definidos como, por exemplo, a alternância dativa em inglês e as unidades de natureza altamente arbitrária (preposições e a atribuição do género dos nomes).

\section{METODOLOGIA}

Neste artigo, adota-se uma abordagem metodológica qualitativa apesar de se ter recorrido ao critério quantitativo para a formulação de hipóteses sobre as áreas críticas do conhecimento gramatical dos aprendentes do português em Moçambique. Tal como referem Larsen-Freeman e Long (1991, p. 11-13), diferentemente do que sucede na pesquisa quantitativa, a pesquisa qualitativa é aquela em que os investigadores não procuram testar hipóteses, mas observam os factos que os rodeiam de modo a desenvolver generalizações empíricas. ${ }^{3}$

Nesse sentido, a base empírica para a realização deste estudo é constituída por dados naturais extraídos de um corpus-amostragem ${ }^{4}$ de 16 entrevistas semi-estruturadas

\footnotetext{
${ }^{3}$ Note-se, porém, que, este tipo de pesquisa, não elimina a existência de um quadro teórico que direcione a recolha, análise e a interpretação dos dados.

${ }^{4}$ Para a constituição deste corpus-amostragem, foram selecionadas quatro entrevistas por província ( 2 de informantes de cada sexo) e o critério para a sua seleção foi o número de palavras produzidas por entrevista, sendo que, para cada província, foram selecionadas as que apresentavam maior número de palavras.
}

Revista X, v. 16, n. 6, p. 1414-1433, 2021. 
(cerca de 17500 palavras), retiradas de um conjunto de 60 entrevistas a alunos da $5^{\text {a }}$ classe das províncias de Cabo Delgado, Zambézia, Maputo-Cidade e Maputo-Província (15 entrevistas por província) em representação das zonas norte, centro e sul do país. A escolha de alunos da $5^{\text {a }}$ classe como população-alvo para a presente pesquisa deve-se ao facto de se considerar que estes aprendentes do português se encontram num estágio intermediário de aquisição desta língua.

As entrevistas foram efetuadas por uma equipa de investigadores do Instituto Nacional de Desenvolvimento da Educação no âmbito do Projeto Avaliação Educacional da qual o autor deste artigo fez parte. Elas tinham como objetivo recolher informação sobre a competência linguístico-comunicativa dos alunos da $5^{\mathrm{a}}$ classe, tendo em vista a melhoria do processo de ensino-aprendizagem desta língua. Com uma duração entre 15 e 20 minutos, tais entrevistas consistiram na solicitação aos alunos que (i) descrevessem rotinas dos fins de semana em casa, na zona residencial ou noutra; (ii) relatassem experiências pessoais relacionadas com "brincadeiras de mau gosto", acidentes de viação, incêndios, lutas entre meninos; (iii) narrassem ou recontassem uma história conhecida e (iv) descrevessem uma sequência de imagens previamente apresentada aos alunos.

Tendo em vista a descrição dos dados, foi feita uma identificação, agrupamento e quantificação dos principais desvios produzidos pelos informantes, à luz da tipologia adotada por Gonçalves $(1997)^{5}$ que prevê quatro grandes áreas linguísticas de classificação, nomeadamente, léxico, léxico-sintaxe, sintaxe e morfossintaxe. Assumese que esta grelha proporciona um quadro indicativo das principais áreas gramaticais em que os aprendentes apresentam mais dificuldades, captando as áreas críticas da competência linguística em português da população auscultada. Por conseguinte, ela permite caracterizar propriedades específicas da gramática da interlíngua dos aprendentes, base imprescindível para a sua posterior utilização na planificação do processo de ensinoaprendizagem da língua-alvo. Assim, na área do léxico, foram identificados os desvios que se referem às unidades lexicais. No domínio do léxico-sintaxe, foram integrados os casos em que a alteração das propriedades dos itens lexicais dá origem a estruturas sintáticas desviantes relativamente à norma do $\mathrm{PE}$. Na sintaxe, foram agrupados os casos que resultam da aplicação de regras sintáticas distintas da norma europeia. Finalmente, quanto à morfossintaxe, foram incluídos os casos relacionados com o uso da morfologia

\footnotetext{
${ }^{5}$ Trata-se de uma grelha tipológica usada no âmbito do "Projecto Panorama do Português Oral de Moçambique" (PPOM) cujo objectivo era constituir um corpus de língua oral que fosse representativo da comunidade moçambicana de locutores de Português. Com mais ou menos adaptações, essa grelha foi usada em vários outros estudos sobre o português de Moçambique (Siopa et al., 2003; Gonçalves, 2010b) e Europeu (Leiria, 2006).
} 
flexional que exprime as categorias gramaticais de tempo, pessoa, número, género, modo e caso.

Para cada uma destas grandes áreas, os desvios foram classificados em diferentes subtipos, tendo em vista tornar mais clara a sua natureza. O quadro 1 apresenta uma caracterização dos tipos de desvios por área:

Quadro 1: Caracterização dos tipos de desvio por área.

\begin{tabular}{|c|c|c|}
\hline Área & Tipo de desvio & Caracterização do tipo de desvio \\
\hline \multirow{3}{*}{ Léxico } & $\begin{array}{l}\text { Neologismo } \\
\text { semântico }\end{array}$ & $\begin{array}{c}\text { utilização, com sentido diferente de palavras } \\
\text { existentes no PE }\end{array}$ \\
\hline & $\begin{array}{l}\text { Neologismo de } \\
\text { forma }\end{array}$ & $\begin{array}{l}\text { criação de novas palavras a partir da aplicação de } \\
\text { regras de formação de palavras existentes no PE }\end{array}$ \\
\hline & Empréstimo & uso de palavras de outras línguas \\
\hline \multirow{7}{*}{ Léxico-sintaxe } & Seleção categorial & alteração da regência dos itens lexicais \\
\hline & Seleção semântica & $\begin{array}{l}\text { escolha incorrecta - do ponto de vista semântico e } \\
\text { não categorial - de complementos de verbo }\end{array}$ \\
\hline & Passivas & má formação de frases passivas \\
\hline & $\begin{array}{l}\text { Pronome pessoal } \\
\text { reflexo }\end{array}$ & $\begin{array}{l}\text { omissão do pronome de flexão reflexiva associado à } \\
\text { posições argumentais }\end{array}$ \\
\hline & $\begin{array}{l}\text { Expressões } \\
\text { temporais }\end{array}$ & $\begin{array}{l}\text { alteração da regência dos chamados complementos } \\
\text { circunstanciais de tempo } \\
\text { escolha lexical relacionada com a expressão de } \\
\text { intervalos de tempo }\end{array}$ \\
\hline & $\begin{array}{l}\text { Expressões } \\
\text { quantitativas }\end{array}$ & $\begin{array}{c}\text { alteração do formato de expressões de gradação, } \\
\text { que inclui o grau dos adjectivos e a escolha dos } \\
\text { quantificadores }\end{array}$ \\
\hline & $\begin{array}{l}\text { Expressões } \\
\text { Recíprocas }\end{array}$ & $\begin{array}{c}\text { omissão do pronome de flexão reflexiva que permite } \\
\text { exprimir a reciprocidade }\end{array}$ \\
\hline
\end{tabular}




\begin{tabular}{|c|c|c|}
\hline \multirow{5}{*}{ Sintaxe } & Encaixe & $\begin{array}{l}\text { alteração do formato de estruturas sintáticas que } \\
\text { contenham diferentes tipos de orações subordinadas }\end{array}$ \\
\hline & $\begin{array}{l}\text { Colocação de } \\
\text { Pronomes Pessoais } \\
\text { Átonos }\end{array}$ & $\begin{array}{l}\text { desvio ao nível do padrão de colocação de pronomes } \\
\text { pessoais átonos }\end{array}$ \\
\hline & Uso dos artigos & omissão de artigo \\
\hline & Determinação & $\begin{array}{c}\text { a determinação do nome é expressa pela flexão do } \\
\text { nome em número (singular ou plural) e não pela } \\
\text { presença de determinante como previsto na norma } \\
\text { europeia }\end{array}$ \\
\hline & Ordem de palavras & inversão da ordem de palavras \\
\hline \multirow{6}{*}{ Morfossintaxe } & $\begin{array}{l}\text { Concordância } \\
\text { Verbal }\end{array}$ & $\begin{array}{l}\text { flexão do verbo em número e/ou pessoa que não está } \\
\text { de acordo com a norma europeia }\end{array}$ \\
\hline & $\begin{array}{l}\text { Concordância } \\
\text { nominal }\end{array}$ & $\begin{array}{l}\text { ausência concordância (de nomes, adjectivos e } \\
\text { determinantes) em género e em número }\end{array}$ \\
\hline & Modo Verbal & desvios em que o modo verbal é afectado \\
\hline & Tempo Verbal & desvios em que os tempos verbais são afectados \\
\hline & Infinitivo & $\begin{array}{l}\text { casos em que se regista o emprego da forma não } \\
\text { flexionada em contextos em que se devia ser usada a } \\
\text { forma flexionada }\end{array}$ \\
\hline & $\begin{array}{l}\text { Flexão casual dos } \\
\text { pronomes pessoais } \\
\text { átonos }\end{array}$ & $\begin{array}{l}\text { casos em que é usada uma forma de flexão casual } \\
\text { inapropriada }\end{array}$ \\
\hline
\end{tabular}

Fonte: Carlito Companhia.

O quadro 2 sintetiza os dados sociolinguísticos dos informantes que produziram o corpus tomado como base para a presente investigação. Esta informação foi recolhida com recurso a uma ficha do informante administrada no âmbito da recolha de dados. 
Quadro 2: Perfil sociolinguístico dos informantes.

\begin{tabular}{|c|c|c|c|c|c|c|c|c|c|c|c|}
\hline \multirow{3}{*}{\multicolumn{2}{|c|}{$\begin{array}{c}\text { Variável } \\
\text { sociolinguística }\end{array}$}} & \multicolumn{10}{|c|}{ Província } \\
\hline & & \multicolumn{2}{|c|}{ Zambézia } & \multicolumn{2}{|c|}{ C. Delgado } & \multicolumn{2}{|c|}{ P. Maputo } & \multicolumn{2}{|c|}{ C. Maputo } & \multicolumn{2}{|c|}{ Total } \\
\hline & & $\mathrm{N}^{0}$ & $\%$ & $\mathbf{N}^{\mathbf{o}}$ & $\%$ & $\mathbf{N}^{0}$ & $\%$ & $\mathbf{N}^{\mathbf{o}}$ & $\%$ & $\mathbf{N}^{0}$ & $\%$ \\
\hline \multirow[t]{2}{*}{ Sexo } & $\mathbf{M}$ & 2 & 13 & 2 & 13 & 2 & 13 & 2 & 13 & 8 & 50 \\
\hline & $\mathbf{F}$ & 2 & 13 & 2 & 13 & 2 & 13 & 2 & 13 & 8 & 50 \\
\hline \multirow[t]{5}{*}{ Idade } & 9 & 0 & 0 & 0 & 0 & 0 & 0 & 1 & 6.5 & 1 & 6 \\
\hline & 10 & 0 & 0 & 0 & 0 & 0 & 0 & 0 & 0 & 0 & 0 \\
\hline & 11 & 0 & 0 & 0 & 0 & 3 & 19 & 0 & 0 & 3 & 19 \\
\hline & 12 & 1 & 6.5 & 0 & 0 & 0 & 0 & 1 & 6.5 & 2 & 12 \\
\hline & $\geq 13$ & 3 & 13 & 4 & 25 & 1 & 6 & 2 & 13 & 10 & 63 \\
\hline \multirow[t]{2}{*}{ L1 } & LB & 4 & 25 & 0 & 0 & 1 & 6 & 2 & 13 & 7 & 44 \\
\hline & Port. & 0 & 0 & 4 & 25 & 3 & 19 & 2 & 13 & 9 & 56 \\
\hline
\end{tabular}

Fonte: Carlito Companhia.

\section{APRESENTAÇÃO DOS DADOS}

À luz da tipologia de desvios adoptada, a análise dos dados permitiu verificar a ocorrência de estruturas desviantes com respeito à norma do $\mathrm{PE}$ ao nível de diferentes componentes da gramática, nomeadamente léxico, léxico-sintaxe, sintaxe e morfossintaxe (cf. Anexo I - Amostragem de desvios). Reconhecendo o facto de no domínio da Linguística Aplicada e do ensino tradicional da gramática haver uma tendência para se considerarem os níveis do léxico, (morfo-)sintaxe e semântica como categorias de análise, neste trabalho, opta-se por uma análise separada dos aspectos do léxico, sintaxe e os fenômenos de interface léxico-sintaxe e morfossintaxe. Ao optar estas duas últimas categorias, pretende-se, por um lado, captar os desvios relacionados com a alteração do formato sintático das frases que decorrem das alterações das propriedades das unidades lexicais e, por outro, os casos em que a aplicação da "morfologia" tem efeitos ao nível da sintaxe, respectivamente.

Assim, no que concerne à área do léxico, verificou-se a ocorrência de neologismos de forma (1a), neologismos semânticos (1b) e empréstimos (1c). Exemplos:

1) a. Às vezes batem-lhe se fazer uma coisa ingostosa. (= ... feia). 
b. Aquele calou não se mostrou (=...denunciou).

c. Depois nhola de novo (=... atira a bola).

$\mathrm{Na}$ área do léxico-sintaxe, os tipos de desvios identificados dizem respeito à alteração das propriedades de seleção categorial (2a) e seleção semântica (2b), às construções passivas ( $2 \mathrm{c})$, ao pronome pessoal reflexo (2d), às expressões locativas (2e), às expressões temporais (2f), às expressões quantitativas $(2 \mathrm{~g})$, às expressões recíprocas (2h) e, finalmente, a atribuição do género dos nomes (2i). Exemplos:

2) a. Concordaram no que a professora disse. (=...com o que ...).

b. Outros rapazes gostam de comer comida. (=...comer).

c. A casa foi queimada com marido dela. (=...pelo marido dela).

d. E o menino despediu a mãe (=...despediu-se da mãe).

e. Um lugar ficam dois meninos (= Num lugar...).

f. Uns tempos vou na machamba (= Às vezes...).

g. É porque você é forte do mundo (=...o mais forte).

h. Um empurrar aí para não se lutarem (=...lutarem).

i. Então a guarda era o macaco (=...o guarda...).

$\mathrm{Na}$ área da sintaxe, foram registados casos de encaixe de orações subordinadas (3a), da colocação dos pronomes pessoais átonos (3b), do uso dos artigos (3c) e de determinação (3d). Exemplos:

3) a. Viu ele não estava a sair ali. (= Viu que ele...).

b. Apanhei nervos e comecei a lhe bater (=...bater-lhe).

c. Manda esta carta para namorado (= ...o namorado).

d. Agora eu vou levar lenhas (=...lenha).

$\mathrm{Na}$ área da morfossintaxe, foram identificados os casos de concordância nominal e verbal (4a-b), de escolha do tempo verbal (4c), de flexão do infinitivo (4d) e de flexão casual dos pronomes pessoais (4e). Exemplos:

4) a. Aquele ali Elsinha estava ali sentada em baio (= Aquela...).

b. E na mesa haviam garrafas, copos e pratos (=...havia...).

c. Levaram o homem e ir deixar no cadeia (=...foram...).

d. Vamos matar e levarmos a cabeça (=...levar...). 
e. Depois a hiena lhe pôs na cadeira (=...pô-lo).

O quadro 3 apresenta dados quantitativos referentes aos desvios identificados em cada uma das áreas gramaticais analisadas.

Quadro 3: Dados quantitativos referentes aos desvios identificados.

\begin{tabular}{|c|c|c|c|c|c|}
\hline \multirow{3}{*}{ Área } & \multirow{3}{*}{ Tipo de desvio } & \multicolumn{4}{|c|}{ Total } \\
\hline & & \multicolumn{2}{|c|}{$\mathrm{N}^{0}$ de ocorrências } & \multicolumn{2}{|c|}{ Percentagem } \\
\hline & & $\begin{array}{c}\text { Tipo de } \\
\text { desvio }\end{array}$ & Área & $\begin{array}{c}\text { Tipo de } \\
\text { desvio }\end{array}$ & Área \\
\hline \multirow{3}{*}{ Léxico } & Neologismos de forma & 18 & \multirow{3}{*}{97} & 19 & \multirow{3}{*}{12} \\
\hline & Neologismos semânticos & 75 & & 77 & \\
\hline & Empréstimos & 4 & & 4 & \\
\hline \multirow{9}{*}{ Léxico-Sintaxe } & Seleção categorial & 175 & \multirow{9}{*}{261} & 67 & \multirow{9}{*}{32} \\
\hline & Seleção semântica & 5 & & 2 & \\
\hline & Passiva & 13 & & 5 & \\
\hline & Expressões locativas & 8 & & 3 & \\
\hline & Expressões quantitativas & 6 & & 2 & \\
\hline & Expressões temporais & 7 & & 3 & \\
\hline & Expressões recíprocas & 1 & & 1 & \\
\hline & Pronome pessoal reflexo & 24 & & 9 & \\
\hline & Género & 22 & & 8 & \\
\hline \multirow{5}{*}{ Sintaxe } & Pronome pessoal - colocação & 31 & \multirow{5}{*}{178} & 17 & \multirow{5}{*}{23} \\
\hline & Encaixe & 49 & & 28 & \\
\hline & Determinação & 5 & & 3 & \\
\hline & Artigo & 82 & & 46 & \\
\hline & Ordem de palavras & 11 & & 6 & \\
\hline \multirow{6}{*}{ Morfossintaxe } & Concordância verbal & 44 & \multirow[b]{6}{*}{224} & 20 & \multirow{6}{*}{28} \\
\hline & Concordância nominal & 31 & & 14 & \\
\hline & Infinitivo & 10 & & 4 & \\
\hline & Tempo verbal & 98 & & 44 & \\
\hline & Pronome pessoal - flexão & 16 & & 7 & \\
\hline & Formas de tratamento & 25 & & 11 & \\
\hline Dispersos & & 43 & 43 & 5 & 5 \\
\hline & Total Geral & 811 & & 811 & 100 \\
\hline
\end{tabular}

Fonte: Carlito Companhia. 
O quadro 3 mostra que, de um modo geral, as áreas da gramática do português que colocam mais dificuldades aos informantes são as do léxico-sintaxe (32\%), da morfossintaxe (28\%) e da sintaxe $(23 \%)$.

\section{DESCRIÇÃO DOS DADOS}

Nesta secção, faz-se uma descrição das principais propriedades da gramática de interlíngua dos aprendentes com particular destaque aos desvios mais frequentes em cada área gramatical nomeadamente léxico-sintaxe (subsecção 5.1.), morfossintaxe (subsecção 5.2.) e sintaxe (subecção 5.3.).

\subsection{Léxico-sintaxe}

Como se viu, na área do léxico-sintaxe, predominam desvios que revelam uma alteração das propriedades de seleção categorial dos itens lexicais. A caracterização destes desvios permitiu identificar quatro grandes grupos de fenómenos. O primeiro refere-se à escolha de uma preposição diferente daquela que é requerida pela norma do PE (SPx $\rightarrow$ SPy) (5a). O segundo envolve os casos em que se verifica a transitivização de verbos com a adoção do padrão [V SN] para verbos que requerem o padrão [V SP] no PE (SN $\rightarrow \mathrm{SPx}$ ) (5b). O terceiro integra os casos em que se verifica ou a inserção de preposições complementos nominais do $\mathrm{PE}(\mathrm{SPx} \rightarrow \mathrm{SN})$ (5c) ou a regência por preposição de complementos frásicos ( $\mathrm{SPx} \rightarrow \mathrm{F}$ ) (5d). Finalmente, o quarto grupo refere-se às formas verbais complexas construídas com um verbo auxiliar, destacando-se a tendência para o

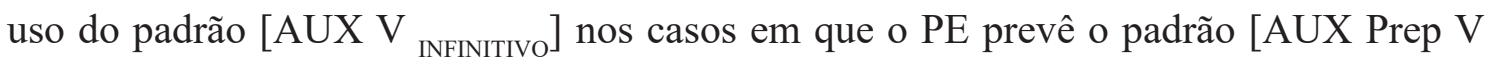
infinitivo $]$ (5e) ou a escolha do padrão [AUX Prep $\mathrm{V}_{\text {Infinitivo }}$ em vez do [AUX V Infinitivo $_{\text {[ }}$ ] (5f). Exemplos:

5) a. Quando eu volto da escola vou em casa (=...para...).

b. Tiraram um pouco de arroz deram os cães (=...aos...).

c. A mãe lhe manda varrer no pátio ele nega (=...o pátio...).

d. Enquanto sabe de que ele é casado (=...que...).

e. Já mamã está começar a fritar (=....está a começar...).

f. Costumo a fazer os meus deveres (= Costumo fazer...).

O quadro 4 sintetiza a informação quantitativa resultante da análise dos casos de seleção categorial. 
Quadro 4: Dados quantitativos na categoria "Seleção Categorial"6.

\begin{tabular}{|c|c|c|c|c|c|c|}
\hline Tipo de desvio & Subtipo & & Total & $\%$ & Subtotal & $\%$ \\
\hline \multirow[t]{9}{*}{ Grupo I: SPx $\rightarrow$ SPy } & $\mathrm{SP}_{\mathrm{em}}$ & $\rightarrow \mathrm{SP}_{\mathrm{a}}$ & 43 & 24.6 & \multirow{9}{*}{76} & \multirow{9}{*}{43.4} \\
\hline & $\mathrm{SP}_{\mathrm{em}}$ & $\rightarrow \mathrm{SP}_{\text {para }}$ & 11 & 6.3 & & \\
\hline & $\mathrm{SP}_{\mathrm{em}}$ & $\rightarrow \mathrm{SP}_{\text {com }}$ & 2 & 1.1 & & \\
\hline & $\mathrm{SP}_{\mathrm{em}}$ & $\rightarrow \mathrm{SP}_{\mathrm{de}}$ & 8 & 4.5 & & \\
\hline & $\mathrm{SP}_{\text {com }}$ & $\rightarrow \mathrm{SP}_{\mathrm{a}}$ & 4 & 2.3 & & \\
\hline & $\mathrm{SP}_{\text {com }}$ & $\rightarrow \mathrm{SP}_{\mathrm{de}}$ & 2 & 1.1 & & \\
\hline & $\mathrm{SP}_{\mathrm{de}}$ & $\rightarrow \mathrm{SP}_{\text {por }}$ & 2 & 1.1 & & \\
\hline & $\mathrm{SP}_{\text {por }}$ & $\rightarrow \mathrm{SP}_{\mathrm{em}}$ & 2 & 1.1 & & \\
\hline & $\mathrm{SP}_{\text {para }}$ & $\rightarrow \mathrm{SP}_{\mathrm{a}}$ & 2 & 1.1 & & \\
\hline \multirow[t]{5}{*}{ Grupo II: $\mathbf{S N} \rightarrow \mathbf{S P x}$} & $\mathrm{SN}$ & $\rightarrow \mathrm{SP}_{\mathrm{em}}$ & 31 & 17.7 & \multirow{5}{*}{62} & \multirow{5}{*}{35.4} \\
\hline & SN & $\rightarrow \mathrm{SP}_{\text {com }}$ & 9 & 5.1 & & \\
\hline & SN & $\rightarrow \mathrm{SP}_{\mathrm{a}}$ & 10 & 5.7 & & \\
\hline & $\mathrm{SN}$ & $\rightarrow \mathrm{SP}_{\mathrm{de}}$ & 8 & 4.5 & & \\
\hline & $\mathrm{SN}$ & $\rightarrow \mathrm{SP}_{\text {por }}$ & 4 & 2.3 & & \\
\hline \multirow{4}{*}{$\begin{array}{l}\text { Grupo III: } \\
\text { SPx } \rightarrow \text { SN/F }\end{array}$} & $\mathrm{SP}_{\mathrm{a}}$ & $\rightarrow \mathrm{SN}$ & 2 & 1.1 & \multirow{4}{*}{19} & \multirow{4}{*}{10.9} \\
\hline & $\mathrm{SP}_{\mathrm{em}}$ & $\rightarrow \mathrm{SN}$ & 1 & 0.6 & & \\
\hline & $\mathrm{SP}_{\text {com }}$ & $\rightarrow \mathrm{SN}$ & 1 & 0.6 & & \\
\hline & $\mathrm{SP}_{\mathrm{de}}$ & $\rightarrow \mathrm{F}$ & 15 & 8.6 & & \\
\hline \multirow{2}{*}{$\begin{array}{l}\text { Grupo IV: Formas } \\
\text { verbais complexas }\end{array}$} & Aux Inf & $\rightarrow$ AuxPrepInf & 10 & 5.7 & \multirow[b]{2}{*}{18} & \multirow[b]{2}{*}{10.3} \\
\hline & Aux Prep Inf & $\rightarrow$ Aux Inf & 8 & 4.5 & & \\
\hline Total & & & 175 & 100 & 175 & 100 \\
\hline
\end{tabular}

Fonte: Carlito Companhia.

Os dados apresentados no quadro acima mostram que, em primeiro lugar, a maior parte dos desvios de seleção categorial diz respeito aos casos do grupo I (43.4\%) e II (35.4\%). No primeiro caso, destacam-se os casos em que os informantes escolhem a preposição em ao invés da preposição $a$, prevista na norma do PE (24.6\%). No segundo

\footnotetext{
${ }^{6}$ Neste quadro, o símbolo $\rightarrow$ quer dizer "em contextos em que o PE seleciona...". Por exemplo $\mathrm{SP}_{\mathrm{em}} \rightarrow \mathrm{SP}_{\mathrm{a}}$ significa que no corpus ocorre um SP regido pela preposição em em contextos em que o PE prevê um SP regido pela preposição $a$.
} 
caso, sobressai a tendência para a transitivização de verbos que, no PE, selecionam complementos preposicionados introduzidos pela preposição em $(17.7 \%)$.

\subsection{Morfossintaxe}

Nesta área, predominam desvios relacionados com o uso do tempo verbal, destacando-se o uso do presente em vez de outros tempos (6a), o uso de uma forma infinitiva quando se trata do padrão [QUANDO/SE+ V], em que devia ser usado o futuro do conjuntivo (6b-c), com a flexão quer de verbos regulares, quer de verbos irregulares (6d-e) e com o uso de infinitivo em vez do presente (6f). Exemplos:

6) a. Anda e lá em América havia um amigo dele (= Foi...).

b. Quando eu fazer anos (=...fizer...).

c. Se termos tempo mais longo vamos assistir (=...tivermos).

d. Atrasíamos a tirar aquelas coisas (=Atrasámos...).

e. Quando eu pido a minha prima (=...peço...).

f. Quando eu vir do mercado tomar banho (= ...venho...tomo...).

O quadro 5 apresenta a informação quantitativa relativa aos desvios ao nível da morfossintaxe.

Quadro 5: Dados quantitativos referentes aos desvios na categoria "Tempo Verbal".

\begin{tabular}{|c|c|c|}
\hline Tipo de desvio & Total & $\%$ \\
\hline Uso do presente em vez de outros tempos & 14 & 14.3 \\
\hline Uso do infinitivo em vez do presente & 40 & 40.8 \\
\hline Uso do padrão QUANDO/SE+V & 32 & 32.7 \\
\hline Flexão de verbos irregulares & 12 & 12.2 \\
\hline Total & 98 & 100 \\
\hline
\end{tabular}

Fonte: Carlito Companhia.

De acordo com o quadro acima, a maior parte dos desvios diz respeito aos casos que envolvem o uso do infinitivo em vez do presente com $40.8 \%$ do total dos casos. 


\subsection{Sintaxe}

No domínio da sintaxe, destacam-se os casos relacionados com a omissão do artigo definido (7a) e indefinido (7b) e com os mecanismos envolvidos no encaixe de orações completivas (7c), relativas (7d) e do discurso direto (7e). Exemplos:

7) a. Ajudar a mamã descascar mandioca (= ...a mandioca).

b. Ao chegar no rio levou cesto pôs no chão. (= ...um cesto...).

c. Viu ele não estava a sair ali (=...que ele...).

d. Havia uma escola que se ensinava ladrões (=...onde...).

e. Disse que 'eu não quero comer' (= ...disse: eu não quero.../disse que ela não queria...).

No que se refere à omissão de artigo, conforme revela o quadro 6, destacase a tendência para a omissão do artigo definido em SNs com a função de complemento direto $(44 \%)$.

Quadro 6: Dados quantitativos referentes aos desvios na categoria "Artigo".

\begin{tabular}{|c|c|c|c|}
\hline Tipo de desvio & Contexto sintático & Total & $\%$ \\
\hline \multirow{2}{*}{$\begin{array}{c}\text { Omissão de artigo } \\
\text { definido }\end{array}$} & SN com a função de Sujeito & 18 & 22.0 \\
\cline { 2 - 4 } & SN com a função de Objecto Directo & 36 & 44.0 \\
\hline $\begin{array}{c}\text { Omissão de artigo } \\
\text { indefinido }\end{array}$ & SN com a função de Sujeito & 10 & 12.0 \\
\cline { 2 - 4 } & SN com a função de Objecto Directo & 18 & 22.0 \\
\hline \multicolumn{2}{|c|}{ Total } & 82 & 100 \\
\hline
\end{tabular}

Fonte: Carlito Companhia.

Relativamente ao encaixe, verifica-se que os casos mais frequentes dizem respeito à omissão do introdutor de subordinação (42.8\%). O quadro 7 apresenta a informação quantitativa referente aos casos de encaixe. 
Quadro 7: Dados quantitativos referentes aos desvios na categoria "Encaixe".

\begin{tabular}{|c|c|c|c|}
\hline \multicolumn{2}{|c|}{ Tipo de desvio } & Total & $\%$ \\
\hline \multirow{2}{*}{ Orações subordinadas relativas } & Omissão do introdutor & 21 & 42.8 \\
\cline { 2 - 4 } & Escolha do introdutor & 19 & 38.8 \\
\hline Encaixe de discurso direto & & 9 & 18.4 \\
\hline Total & & 49 & 100 \\
\hline
\end{tabular}

Fonte: Carlito Companhia.

\section{CONSIDERAÇÕES FINAIS}

Este estudo tinha como objectivo descrever as áreas críticas na aquisição do português em Moçambique. Para alcançar este efeito, do ponto de vista metodológico, esta pesquisa adotou uma abordagem qualitativa apesar de que as hipóteses foram formuladas com base na observação de dados quantitativos. Ela tomou como base um corpus-amostragem constituído por 16 entrevistas semi-estruturadas produzidas por alunos da $5^{\text {a }}$ classe em Moçambique aprendentes do português.

Os resultados deste estudo mostram que, nesta fase do seu desenvolvimento linguístico, as áreas críticas da gramática de interlíngua dos aprendentes do português em Moçambique se situam ao nível do léxico-sintaxe, morfossintaxe e sintaxe. Em primeiro lugar, na área do léxico-sintaxe, destaca-se a alteração das propriedades de seleção categorial, e de um modo particular, a escolha de uma preposição diferente daquela que é requerida pela norma do $\mathrm{PE}$ e a tendência de transitivização dos verbos que no $\mathrm{PE}$ selecionam complementos preposicionados. Em segundo lugar, ao nível da morfossintaxe, pode referir-se à escolha do tempo verbal, destacando-se o uso do infinitivo em vez do presente. Em terceiro lugar, no domínio da sintaxe, salienta-se a omissão do artigo com particular referência à tendência para a omissão do artigo com SNs que desempenham a função sintática de complemento direto e o encaixe de orações subordinadas, onde sobressaem aspectos relacionados com a omissão do introdutor de subordinação.

Assumindo que o ensino da gramática deve também ter em consideração a forma como os aprendentes desenvolvem as suas interlínguas no processo de aquisição, os resultados desta pesquisa podem contribuir para o desenho de estratégias de intervenção didática que possam garantir o processo de reestruturação gramatical das hipóteses que emergem durante o desenvolvimento linguístico dos aprendentes neste estágio de aquisição. 
Isto é particularmente importante na medida em que tanto quanto a pesquisa sobre o PM já demonstrou (cf. GONÇALVES, 2010a), logo nos primeiros estágios de desenvolvimento linguístico, verifica-se a emergência de hipóteses divergentes relativamente ao PE que acabam por ser retidas no estágio final de aquisição do PM, revelando que o processo de reestruturação gramatical não altera substancialmente as hipóteses iniciais. Assim, tendo em consideração que a maximização dos efeitos benéficos do ensino da gramática ocorre a partir dos estágios intermediários da aquisição de uma língua (ELLIS, 2002), sugere-se a incorporação destes tópicos nos programas de português do ensino básico como forma de reduzir as possibilidades de fossilização das estruturas identificadas como problemáticas.

Para concluir este estudo sobre as áreas críticas na aquisição do português em Moçambique, sugere-se que sejam levados a cabo estudos da mesma natureza com alunos de outras classes como uma forma de sistematizar aspectos relacionados com o desenvolvimento linguístico dos aprendentes que frequentam os diferentes níveis de ensino. A par destes estudos, recomenda-se também a realização de trabalhos de cunho teórico tendo em vista compreender as razões que explicam as diferentes hipóteses que os aprendentes constroem sobre a gramática da sua interlíngua.

\section{REFERÊNCIAS}

COMPANHIA, C. Panorama dos estudos sobre a aquisição do português L2 em Moçambique. Revista Odisseia, Natal, v. 3, n. 1, p. 1-15, jan./jun., 2017.

ELLIS, R. The study of second language acquisition. Oxford: Oxford University Press, 2008 .

. The place of grammar instruction in the second/foreign language curriculum. In: HINKEL, E.; FOTOS, S. (Eds.). New perspectives on grammar teaching in second language classrooms. New Jersey: Laurence Ermaum Associates, 2002. p. 17-34.

GASS, S.; SELINKER, L. Second language acquisition: an introductory course. London: Lawrence Erlbaum, 2001.

GONÇALVES, P. Tipologia de "erros" do português oral de Maputo: um primeiro diagnóstico. In: STROUD, C.; GONÇALVES, P. (Orgs.). Panorama do português oral de Maputo, vol. II - a construção de um banco de "erros". Maputo: Instituto Nacional de Desenvolvimento de Educação, 1997. p. 37-68. 
- The role of ambiguity in second language change: The case of Mozambican African Portuguese. Second Language Research, v. 18, p. 325-347, 2002.

A génese do português de Moçambique. Lisboa: Imprensa Nacional, 2010a.

- Perfil linguístico dos estudantes universitários: áreas críticas e instrumentos de análise. In: GONÇALVES, P. (Org.). O português escrito por estudantes universitários: descrição linguística e estratégias didácticas. Maputo: Livraria Universitária, 2010b. p. 15-50.

; CHIMBUTANE, F. Assimetrias da mudança linguística em contextos pós-coloniais: o caso do português e das línguas bantu em Moçambique. In: GONÇALVES, P. (Org.). Multilinguismo e multiculturalismo em Moçambique: em direcção a uma coerência entre discurso e prática. Maputo: Alcance Editores, 2015. p. 77-101.

GOODLUCK, H. Language acquisition and linguistic theory. In: FLETCHER, P.; GARMAN, M. (Eds.) Language acquisition. Cambridge: Cambridge University Press, 1986. p. 49-68.

KLEIN, E.; MARTOHARDJONO, G. Investigating second language grammars: some conceptual and methodological issues in generative SLA research. In: KLEIN, E.; MARTOHARDJONO, G. (Orgs.). The development of second language grammars: a generative approach. Amesterdam: John Benjamins, 1999. p. 3-34.

KRASHEN, S. 1998. Second language acquisition and second language learning. New York: Prentice Hall International, 1998.

LAKSHMANAN, U.; SELINKER, L. Analysing interlanguage: how do we know what learners know? Second Language Research, v. 17, p. 393-420, 2002.

LARSEN-FREEMAN, D.; LONG, M. An introduction to second language acquisition research. New York: Longman, 1991.

LEIRIA, I. Léxico, aquisição e ensino do português europeu língua não materna. Lisboa: Fundação Calouste Gulbenkian e Fundação para a Ciência e a Tecnologia/ Ministério da Ciência e do Ensino Superior, 2006.

LONG, M. Stabilization and fossilization in interlanguage development. In: DOUGHTY, C.; LONG, M. (Eds.). The handbook of second language acquisition research. Malden: Blackwell Publishers, 2003. p. 487-535. 
ODLIN, T. Cross-linguistic influence. In: DOUGHTY, C.; LONG, M. (Eds.). The handbook of second language acquisition research. Malden: Blackwell Publishers, 2003. p. 436-486.

RAPOSO, E. Teoria da gramática: a faculdade da linguagem. Lisboa: Caminho, 1992.

RITCHIE, W.; BATHIA, T. Second language acquisition: introduction, foundations, and overview. In: RITCHIE, W.; BHATIA, T. (Eds.). Handbook of second language acquisition. San Diego: Academic Press, 1996. p. 1-45.

SELINKER, L. Interlanguage. In: RICHARDS, J. C. (Ed.). Error analysis perspectives on second language acquisition. London: Longman, 1974. p. 34-54.

SIOPA, C.; ERNESTO, N.; COMPANHIA, C. A competência em português dos estudantes universitários em Moçambique: primeira abordagem. Idiomático 1 (Revista Digital de Didáctica PLNM). Instituto de Camões - Centro Virtual Camões, 2003. 


\section{ANEXO I - AMOSTRAGEM DE DESVIOS ${ }^{7}$}

\section{LÉXICO}

1. Chegaram limparam todo dinheiro (= ..roubaram...). (CD. NEL)

2. Aí atrás tinha um elefante. (=...havia...) (CD. NEL)

3. Lutaram quase a noite de manhecer (=...amanhecer). (PZ. JUM)

4. Batem-lhe se fazer uma coisa ingostosa. (=...feia) (PZ. ELD)

5. Magagada estava aí dentro (=...mandioca seca...). (PZ. ELD)

\section{LÉXICO-SINTAXE}

1. Chegaram bateram o miúdo (= ...bateram no miúdo). (CM. LUI)

2. O filho foi na pesca (= ..à pesca). (PM. JOA)

3. É porque você é forte do mundo (= ... o mais forte...). (CD. JUA)

4. Ao andar do tempo (= ...com o andar do tempo). (CD. JUA)

5. Foi amarrado com o coelho (=...pelo coelho). (PZ. JUM)

\section{SINTAXE}

1. Descascar batatas meter hum (= ...as batatas...). (CM. LAT)

2. Vou tentar que apanho (= ...tentar apanhar). (CD. JUA)

3. Disse que "eu não quero comer" (= .. disse: eu não quero...). (PM. ZIT)

4. Ele se mostrou (= ...mostrou-se). (CD. BEN)

5. Atropelou o homem a criança (=...o homem atropelou a criança). (CD. FAD)

\section{MORFOSSINTAXE}

1. Depois levo a frigideira põe no lume (=...ponho...). (CM. LUI)

2. Uma vez ganhámos três bola (= ...três bolas). (CD. FAD)

3. O meu irmão provocou ele (=...provocou-o). (CM. LAT)

4. Quando você apanhas estás no meio dá (=...apanha...está...). (CD. JUA)

5. Se ser um dia de jogo assistimos (=...for...). (PZ. JUM)

\footnotetext{
${ }^{7}$ No final de cada frase, apresenta-se o código do informante que produziu a frase. Assim, as primeiras duas letras indicam a província enquanto as três últimas indicam as iniciais do nome do informante.
} 